\title{
Das Kind auf der antiken Bühne
}

Von

\section{Hans Devrient}

Abhandlung zu dem Jahresberichte des Wilhelm-Ernst-Gymnasiums

Weimar

Druck der Hof-Buchdruckerei

Progr. Nr. 790.

1904

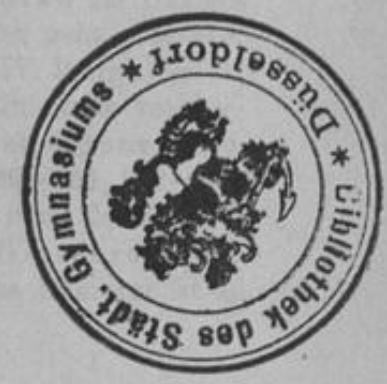





\title{
Das Kind auf der antiken Bühne.
}

\author{
Von
}

\section{Hans Devrient.}

\section{Griechenland. $\left.{ }^{1}\right)$}

$\mathrm{D}$ ie Frage nach der Aufführungsart der uns erhaltenen Dramen alter und neuerer Zeit hat schon so viele Forseher, Philologen, Ästhetiker und Kunsthistoriker, beschäftigt, und doch sind wir über die einfache historische Frage, „wie war es eigentlich“, bei fast allen Völkern aller Zeiten recht wenig unterrichtet. Wir finden in der deutschen Theatergeschichte ebensoviel offene Fragen wie in der griechischen und römischen. Und doch wird auf allen diesen Gebieten fortwährend gearbeitet, sowohl nach der Seite des Technischen hin wie nach der des Literarischen. Gerade über das antike Theater haben wir in letzter Zeit viele Anfklärungen erfahren, sogar an den Versuch einer Entwicklungsgeschichte des volkstümlichen Theaters wagte sich die unermüdliche Forschung heran.

Ein Gebiet der Geschichte der Bühnenkunst scheint noch recht wenig bebaut worden zu sein; ein kleines Gebiet, eine kleine Welt freilich, die aber doch in die gesamte dramatische Kunst oft bedeutungsvoll eingegriffen hat: das Kind auf der Bühne. ${ }^{2}$ ) Nicht das Kind im Drama ist gemeint, darüber ist schon öfter gesprochen worden. Mich interessiert die Frage, wie und von wem sind die Kinderrollen des Dramas a uf der Bühne dargestellt worden? Natürlich steht diese dramaturgische, theatergeschichtliche Frage mit jener literarischen in Zusammenhang.

Wenn ich auch von der Beobachtung moderner Zustände, von der Person des Kindes im modernen Drama und auf der modernen Bühne aus zu diesem Problem gekommen bin und mir seine Durchführung bis zum Christel in Goethes "Geschwistern" und zu G. Hauptmanns „Hannele“ vorbehalten möchte, so muß doch diese wie alle derartigen Untersuchungen einer

1) Die Fortführung des Themas (Rom, Indien), die hier des Raummangels wegen unterbleiben mußte, gedenke ich an anderm Ort zu bringen.

${ }^{2}$ ) Anregend, aber an der Lösung unseres Problems vorbeihuschend ist der Aufsatz von J. E. Poritzky, Das Kind in der Weltliteratur. Lit. Echo, III. Jahrg., Heft 24, Sp. 1665-73. - Das Kind im Dram von A. v. Ga u dy (Bühne u. Welt, I. Jahrg., Nr. 22, S. 543-547) ist eine anmutige Planderei, geht aber ube das antike Bühnenwesen fast ganz hinweg. - Ein anonymer Artikel in Bühne u. Welt, IV. Jahrg., Nr. 12, Märzheft 2, 1902, S. 519-526, über Shakespeares K indergestalten berührt in der Einleitung vorübergehend das antike Theater. - H. Kraeger, Die Figur des Kindes auf der antiken Buhne, Germania. Tijdschrift voor Vlaamsche Beweging etc. Brüssel 1902, Nr. 4-6, S. 203-213, 265-271, 372-381, behandelt nicht die dramaturgische Frage nach der Darstellung, sondern die literarische nach der Dichtergestalt des Kindes im antiken Drama. - C. Haym, De puerorum in re scaenica Graecorum partibus. Diss. Halle 1897, habe ich mit Freude benutat (в. u.). - Die übrige herangezogene Literatur ist an gegebener Stelle zitiert. 
durchgehenden Erscheinung zuerst bei der Antike verweilen. Dort sind alle Verhältnisse einfach, klar durchsichtig und in ihren primitiven Gesetzen für die Erscheinungen der ganzen Folgezeit bei anderen Völkern vorbedeutend.

Kein Bericht über die Darstellung eines Kindes auf der antiken Bühne ist überliefert, keine Ausgrabung spricht von ihr. Was etwa auf den unteritalischen Phlyakenvasen abgebildet ist, hat gar keine Beweiskraft für Verhältnisse des Dramas und besonders des griechischen Theaters. Wir sind für jede Zeit auf die jeweiligen dramatischen Denkmäler angewiesen, ${ }^{1}$ ) d. s. hier die Dramen der drei attischen Tragiker und des Aristophanes, für das römische Theater die des Seneca und der Plautinischen Komödie. Dazu kommen ein paar Splitterchen aus der Mimusliteratur und andere Fragmente. Diese literarischen Denkmäler sind das Material, mit dem wir zu arbeiten haben, aus ihnen gilt es Schlüsse zu suchen auf ihre Darstellungsart.

Aristoteles berichtet in seiner Poetik 4. (Diog. III, 56), anfangs sei der Chor allein aufgetreten, später habe Thespis einen Schauspieler erfunden, um den Chor zu unterbrechen. Einen zweiten Schauspieler habe Aeschylus hinzugefügt, den dritten Sophokles, der damit die

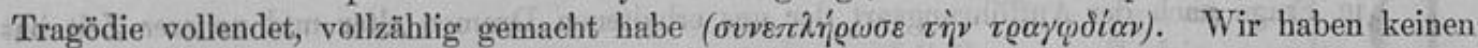
Anlaß, diese Angaben anzuzweifeln. Für ein Kind war bei dieser beschränkten Zahl der Agonisten in den beiden ältesten Stufen des Dramas kein Platz. Und auch Sophokles wird das kömnen wir schon aus diesen Zahlen schlielien - sparsam zurückhaltend mit der Einführung eines Kindes haben vorgehen müssen. Diesen Tatsachen entspricht der Befund in den Dichtungen. Doch ist der Dramatiker überhaupt mit der Verwendung des Kindes ganz anderen Sperrgesetzen unterworfen als der Epiker, auch anderen als der bildende Künstler. ${ }^{2}$ )

In den erhaltenen Tragödien des A eschylu s tritt kein Kind auf. Von den verlorenen, deren Inhalt in allgemeinen Zügen nach den überlieferten Titeln zu erschließen ist, scheint der Telephos, wie der wohl davon abbängige, ebenfalls verlorene Euripideische, ein Kind unter den Personen gehabt zu haben, worauf schon Haym (a. a. O. S. 22 f.) hinweist. Es war der kleine Orest, den Telephos aus der Wiege raubt. Als sicher scheint indessen festzustehen, daß hierzu bei der Aufführung ein Bild, eine Puppe genommen wurde ${ }^{3}$ ) (ähnlich wie vermutlich auch für den riesigen Prometheus oder auch für vorkommende Leichen s. u.), so daß Aeschylus ohne Kinderdarsteller ausgekommen zu sein scheint. Wir dürfen dieses Fehlen des Kindes bei Aeschylus nicht auf eine altertümliche Unbeholfenheit im Überwinden technischer Schwierigkeiten des großen Dichters schieben oder gar auf einen Mangel an Verständnis für das Kindliche. Er hat, wie H. Kräger a. a. O. S. $204 \mathrm{f}$. hübsch zusammenstellt, in erzählenden Teilen seiner Dramen ergreifend wahre Schilderungen des Kindeslebens. So im Agamemnon bei Kassandras Beschreibung von dem gräßlichen Mahl des Thyestes (V. 1213-1221). So die drastische Erzählung der Kindel- und Windelszenen durch Orests Amme in den Choephoren (V. 745-758). Das Vermeiden des Kindes auf der Bühne scheint mir vielmehr mit dem innersten Charakter Aeschyleischer Dichtart eng zusammenzuhängen, mit dem gigantischen, schweren, ja düsteren Ernst seiner Muse. Die rührenden, empfindsamen Züge der tragischen Poesie, in denen gerade das Kind eine so wirkungsvolle Rolle spielen sollte, lagen ihm fern.

1) Vgl. die vortrefflichen Grundsitze in der Einl. zu E. Bethes Prolegomena zur Geschichte des Theaters im Altertum. Leipzig 1896.

2) Vgl. D. Heubach, Das Kind in der griechischen Kunst. Heidelberger Diss. Wiesbaden 1903.

3) Uber ein Herleiten dieser Puppen von der-mimischen Darstellung des neugeborenen Dionysosknaben bei den Eleusinischen Mysterien und bei den Prozessionen zum Choenfest, oder des kleinen Apollon auf dem Arm der Leto bei den Pythien vgl. Heubach S. 6, 8, 10, 55 . 
Er kam gar nicht darauf, jene Weichheit, Schmiegsamkeit und Anmut kindlicher Glieder auf seine Bühne zu bringen, wo nur das GroBe in erhabener Strenge einherschritt.

Aus wesentlich anderem, neuerem Geiste geboren sind die Tragödien des Sophokles und noch mehr dann des Euripides. Und doch standen auch sie der Aufführung ihrer Dramen noch sehr nahe. Sophokles soll zwar selbst nicht mehr als Protagonist aufgetreten sein, aber wir dürfen vermuten, daß er bei den Rollen seiner Stücke an bestimmte Darsteller gedacht hat (vgl. W. Christ, Geschichte der griechisehen Literatur, J. Müllers Hdb. der klass. Altertums-Wissenschaft, Bd. VIII, 1889, S. 174, 176). Er hat das Bild der Darstellung immer vor Augen. Mit vollem Bewußtsein von der Bühnenwirkung wird er also Kinder auf die Bühne gestellt haben und sie handeln und sprechen lassen, oder er wird es vermieden haben aus technischen Gründen nicht der Dichtkunst sondern der Bühnenkunst.

In der Antigone geleitet den Tiresias stumm ein Knabe. Er kommt und geht mit dem blinden Seher, seine Darstellung durch einen statistierenden Knaben bot keinerlei Schwierigkeit.

Im Aias ist das Kind auch stumm, aber nicht unwichtig zur Handlung. Sein Anblick besänftigt des Vorwurfs bittre Pfeile in der Brust des Vaters, und beachtenswert ist, wie der Dichter die an sich wohl undeutliche oder unsichere Aktion des Kindes durch Textworte eines Erwachsenen einführen läßt: Aias bezeichnet der Gattin die Handlung, die sie mit Eurysakes ausführen soll, und dem Söhnchen sagt er, was es später tun, daß es, erwachsen, Schmach und Tod des Vaters rächen soll. So zaubert der Dichter dem Publikum an dem untätigen Kinde durch die Worte der Erwachsenen dramatische Handlung vor. Am Ende des Dramas wird der Knabe nochmals an die Leiche des Vaters gebracht, auch hier ist das Kind stumm, und die Bewegungen werden ihm durch Textworte des Oheims Teukros vorgeschrieben. So kann, ungestört durch ein kindisehes Ungeschick, die Anwesenheit des kleinen Sohnes an der Bahre des Helden als tragische Steigerung wirken.

Im Anfang von König Oedipus sitzt ein Knabenchor mit Ölzweigen um den Altar. Der Oberpriester spricht für sie (vgl. V. 9 f.). Weiterhin tritt Tiresias mit einem Knaben auf,

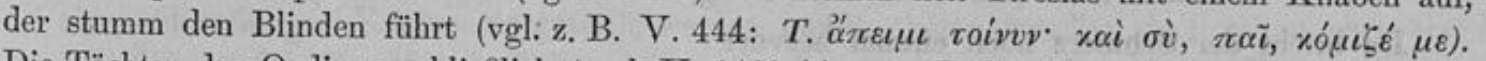
Die Töchter des Oedipus schließlich (nach V. 1462 bis zum Ende), deren Alter übrigens zweifelhaft ist, ${ }^{1}$ ) sind ebenfalls stumm. Auf die inhaltschwere, entsetzliche Mitteilung von ihrer erblichen Belastung haben sie kein Wort zur Erwiderung. Ihr Schluchzen meldet der Vater. Aber allein durch ihre Gegenwart läßt der Dichter die Wirkung des väterlichen Jammers dieser Familientragödie gewaltig erhöhen.

Nach diesen Beispielen zu schließen, verwendet Sophokles Knaben teils als Chor, teils einzeln. Er benutzt sie, um eine stärkere Wirkung, besonders eine wehmütig rührende, traurig ergreifende herbeizuführen, Mitleid und Furcht zu erregen. Diese Wirkung erreicht er, ohne eines der Kinder sprechen oder selbständig handeln zu lassen. Sophokles kennt also noch keine eigentlichen Kinderdarsteller, oder er will sie nicht kennen.

Etwas anders steht es bei Euripides.

In der Alkestis treten die Kinder des Admetos und der Alkestis auf. Sie geleiten an der Seite des Vaters die Mutter auf dem letzten Gange. Stumm und ohne viele eigene Bewegungen, die beim darstellenden Kinde leicht lächerlich wirken könnten, läßt sie der Dichter neben der Mutter hergehen. Die notwendige ungestüme Betätigung des kindlichen Schmerzes aber verlegt er in den Bericht, den vor dem Auftreten der Gruppe die Sklavin von den Vor-

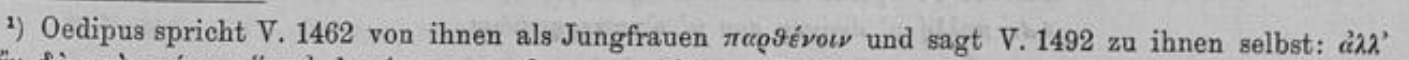

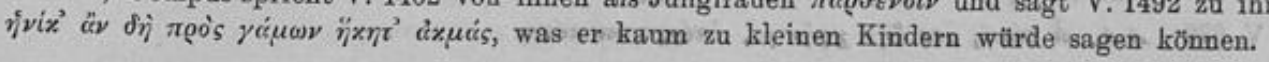


gängen im Innern des Palastes schon vorbereitend gegeben hat. $\mathrm{Da}$ haben die Zuschauer sie schon in Gedanken vor sich gesehen, ganz in der Stimmung und Gebärde wie sie der Dichter braucht: (V. 184 ff. nach J. J. C. Donners Übersetzung. 3 Bde. 3. Aufl. Leipzig-Heidelberg. 1876. $8^{\circ}$. Den griech. Text setze ich zum Vergleichen in die Anmerkung.) ${ }^{1}$ )

Und am Gewand der Mutter hängend weinten laut

Die Kinder; beide nahm sie wohl in ihren Arm,

Eins um das andre küssend, nun sie scheiden soll.

Diese Aktion der Kinder und mit den Kindern wagte Euripides nicht der Darstellung durch Knaben anzuvertranen. Und doch weiß er auch ihr Erscheinen auf dem Theater der Situation dienstbar zu machen. Der bittre Abschiedsschmerz der Mutter wird durch das Losreißen von den Kindern noch vermehrt:

Grauen der Nacht

Beschleicht düster mir die Augen.

Kinder, ach! Kinder, nicht

Mehr, nicht mehr ist eure Mutter! ${ }^{2}$ )

Mütterlich selbstlos treibt sie die Geliebten ins Leben hinein mit dem Schlußsatz: Seht freudig fortan dieses Licht, o Kinder! - Admet ist trostlos, und das höchste, wobei er die Geliebte beschwören kann, nicht in den Tod zu gehen, sind die Kinder:

Bei den Himmlischen fleh' ich, verlaß mich nicht,

Bei den Kinderchen, die dein Scheiden verwaist. ${ }^{3}$ )

Sie muß hinab, und sie übergibt ihm noch die Kinder:

Alkestis: Auf dieses nimm aus meiner Hand die Kinder hin.

Admetos: Die teure Gabe nehm' ich aus der teuren Hand.

Alk.: Sei du den Kindern Mutter jetzt an meiner Statt!

Adm.: Wohl haben sie mich nötig, sind sie dein beraubt. ${ }^{4}$ )

$\mathrm{Da}$ bricht der Schmerz noch einmal hervor:

Alk: Ich sollte leben, Kinder, und ich muß hinab. ${ }^{5}$ )

Auf die Kinder beziehen sich die letzten Worte vor der Trennung:

Adm.: Richt auf das Antlitz! O verlaß die Kinder nicht!

Alk: Ungerne scheid' ich, Kinder: Lebt denn, lebet wohl!

Adm.: Nach ihnen blicke, blicke hin! Alk.; Nicht mehr bin ich.

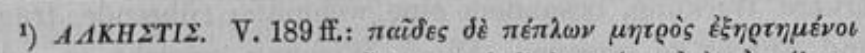

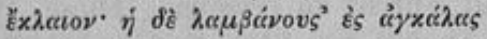

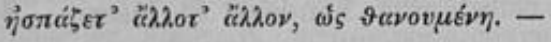

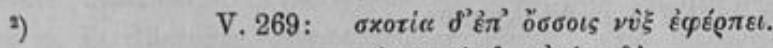

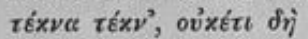

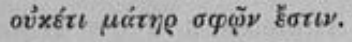

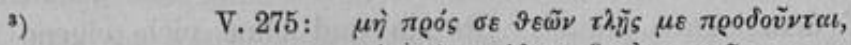

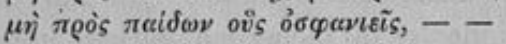

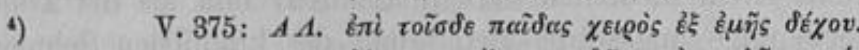

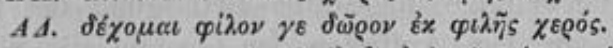

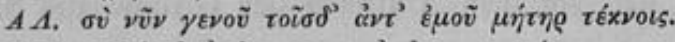

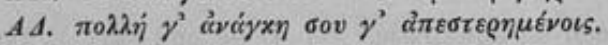

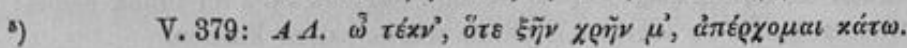


Nur ein kurzer allerletzter Abschied der beiden Gatten folgt.

Adm.: Was willst du? Scheiden? Alk.: Lebe wohl! Adm.: Verlorner ich! Der Chor: Nicht mehr, dahingeschieden ist Admetos Weib. ${ }^{1}$ )

Bis hierher blieben die Kinder stumm in ihrem Schmerz, solange die Mutter unter ihnen war. Als wäre er mit ihrem Tode mündig geworden, bricht jetzt der Sohn in das Totenlied aus: Eumelos: O weh, welches Los!

Meine Mutter ist hinabgegangen, weilt nicht mehr, Vater, im Sonnenlicht;

Sie verliek, die Unselige,

Machte zur Waise mich ... usw. bis V. $415 .{ }^{2}$ )

Das konnte kein Kind darstellen, weder sprechen noch singen. Die Worte sind nicht für einen Kinderdarsteller geschrieben. Sie sind zu schwer, zu tief, die Situation ist zu tragisch. Ein Erwachsener mit jugendlicher Stimme muß es gesprochen haben; ob auch dargestellt, ist eine schwierige Frage. Vom Standpunkt der griechischen dramatischen Technik wäre an sich nichts dagegen einzuwenden, wenn der Tritagonist, der zu Anfang die Sklavin gegeben hatte, sich umgezogen hätte und dann in jugendlicher Maske und Kleidung als Eumelos mit den Eltern und dem Schwesterchen aufgetreten wäre und die Strophen vorgetragen hätte. Spricht doch auch Eumelos für das Schwesterchen, das stumm dabeisteht. Wären beide einfach durch Kinder dargestellt worden, so hätte der Dichter ebensogut wie dem Knaben auch dem Mädchen ein paar Worte der Klage geben können. Allein in haltlich ist es nicht wahrscheinlich, daß ein Erwachsener den Eumelos darstellte. Eumelos ist noch ein Kind. Er ruft aus:

So jung, Vater, schau,

Steh ich einsam, und die teure Mutter fehlt mir. ${ }^{3}$ )

Das mußte durch einen Knaben, nicht durch einen Epheben dargestellt werden. Weshalb aber, fragen wir, redet (oder singt) das Kind dann erst nach der Mutter Tod? Wenn es schon durch einen überzähligen Knaben dargestellt werden mußte, hätte derselbe doch schon eher ein Abschiedswort für die Mutter finden können und müssen. Das ist sehr auffällig. Sollte das nicht mit der Notwendigkeit des Sprechenlassens durch die Stimme eines der erwachsenen Schauspieler zusammenhängen? Wäre nicht denkbar, daß ein Knabe die Figur darstellt und die ganz einfachen Bewegungen ausführt, ein Schauspieler aber auf oder hinter der Szene für ihn vorträgt? Das könnte einer der Choreuten, es könnte es aber auch einer der zurzeit nicht beschäftigten Schauspieler tun. Nur der Admetspieler ist noch sprechend auf der Szene. Der Tritagonist, vorher Sklavin, oder der Alkestisspieler sind zur Verfügung. Beide haben

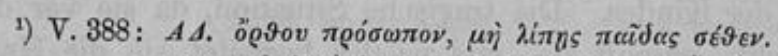

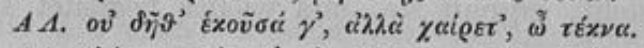

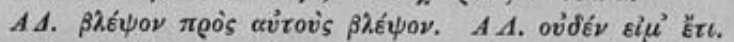

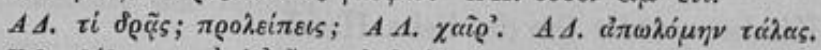

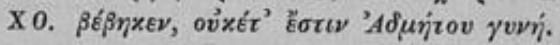

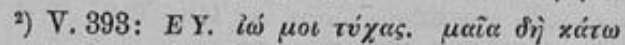

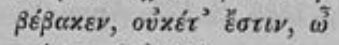

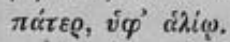

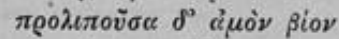

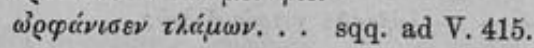

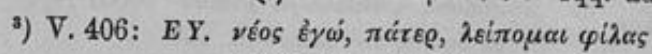

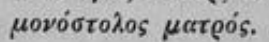


vorher schon mit verstellter hoher Stimme sprechen müssen. Einer von beiden wird es, auf irgendwelche Art cachiert, vorgetragen haben. Damit die beiden verstellten Stimmen, als Alkestis und als Knabe Eumelos nun nicht verwechselt würden, was beim Vortragen für eine dritte Person sehr leicht geschehen konnte, mußte wohl das Kind schweigen, bis die Mutter verstummt war. Das träfe am meisten zu, wenn etwa der Alkestisspieler selbst die Kindesworte genommen hätte; ich halte das durchaus nicht für ausgeschlossen, da die Leiche der Mutter ja erst verdeckt oder, wie z. B. Alb. Müller ${ }^{1}$ ) will, durch ein Bild dargestellt werden konnte. Wenn wir der Ansicht von Elmsley (Classic journ. XVI. 435), G. Hermann (Praef. Alc. XII) und Alb. Müller (Scen. Fragen zu Eur. Alk. Progr. Hannover 1860, S. 4 ff.) folgen und nur zwei Darsteller für unser Drama annehmen wollten, wäre diese Folgerung sogar notwendig. Daher kommt es wohl auch, daß am Schluß, als Alkestis den Thren wiedergegeben wird, die Kinder gar nicht mit dabei sind oder doch nicht reden. Jedenfalls ergibt sich aus alledem die Erkenntnis der Schwierigkeiten, die anch Euripides in der Darstellung von Kinderrollen erblickt zu haben scheint, und die er auf irgend eine Weise zu umgehen, zu überdecken bestrebt war.

Diese Auffassung wird gestützt durch die Beobachtung der Darstellungsart der Kinder in der Medea. Der Fabel des Dramas nach stehen sie noch mehr im Mittelpunkt der ganzen tragischen Situation. Doch ist die merkwürdige Überlieferung zu beachten (Paus. II, 3. 8 und Schol. zu Med. 273), wonach die traurige Lage der Kinder durch die Entzweiung der Eltern zwar schon bei den Epikern Eumelos und Kreophylos erzählt wurde, die Ermordung durch die Mutter aber erst bei den Tragikern vorkäme (vgl. W. Christ, Gesch. d. Griech. Literatur S. 194). Zum Hinweis auf die Tragik der Kinderrollen wird bei Euripides vor ihrem Auftreten schon zu Beginn des Stückes durch die prologisierende Amme der Gegensatz zwischen der Arglosigkeit der Kinder und der ihnen drohenden Gefahr hervorgehoben, als Ouvertüre zum Thema der ganzen Tragödie: Medeas Kindermord. Stumm treten die Knaben dann in Begleitung ihres Pädagogen, der sie vom Gymnasion bringt, auf (V.46-95). Um der verderblichen Raserei der Mutter nicht ausgesetzt zu sein, werden sie von der Amme Medeas beim Auftritt der Mutter ins Haus geschickt: wir sollten nur mit ihnen, den rührenden Opfern der rasenden Mutter, bekannt gemacht werden. Es sind noch richtige unselbständige Kinder, sie sprechen nicht, sie konnten durch Statistenkinder dargestellt werden. So bleibt es durch das ganze Stück: Sie sind wichtige Glieder der Handlung, aber auf der Szene sind sie stumm. Sie werden von der Mutter aus dem Haus gerufen, alles, was sie tun sollen, schreibt ihnen die Mutter vor, als Erklärung ihrer Bewegungen für das Publikum:

$\mathrm{O}$ kommt, umarmt ihn, küsset ihn und redet an

Mit mir den Vater! - - - Ergreift des Vaters rechte Hand! ${ }^{2}$ )

So spricht sie für die Kinder, statt der Kinder. Die tragische Situation, da sie vor dem Mord der geliebten Kinder schaudernd steht, ergreift sie, und wieder begleitet sie die Handlung der Kleinen mit ihren Worten:

$\mathrm{O}$ meine Kinder, werdet ihr die liebe Hand

Noch lange so mir reichen ${ }^{3}$ )

1) Lehrbuch der griechischen Bühnenaltertümer. Freiburg 1886, S. 175, Anm. 2.

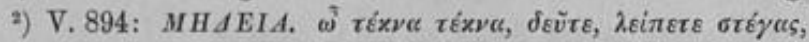

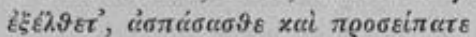

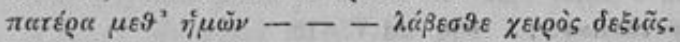

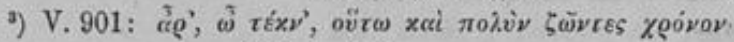

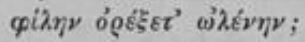


Kein Wort entgegnen die Kinder, keinen Ausruf. Stumm gehen sie wieder mit dem Vater ab, von der Mutter geschickt:

Doch nun, o Kinder, geht hinein ins reiche Haus!

Die neue Frau des Vaters, meine Königin,

Fleht an, erbittet, daß man euch hier bleiben läßt. $\left.{ }^{1}\right)$

Sie werden die Überbringer des verderblichen Geschenks: „und reicht den Schmuck ihr! Hier werden sie sogar einmal Träger einer Handlung. Aber der vorsichtige Dichterregisseur verlegt diese Handlung hinter die Szene. Der Chor begleitet ihren Abgang mit vertiefenden Betrachtungen, das unheimliche Geschick geht mit dem Todesgeschenk seinen Weg. Die Kinder kommen zurück, wieder von ihrem Pädagogen begleitet. Haym macht (a. a. O. S.5) die treffende Bemerkung, daß Kinder auf der Szene fast immer nur in Begleitung Erwachsener auftreten. Euripides läßt die kleinen Darsteller nicht allein erscheinen aus Sorge, sie könnten einen falschen Schritt, eine unpassende Bewegung machen, die dem Ernst des Auftritts verhängnisvoll werden könnte. Die Institution des Paidagogos dient dem Dichter da oft gut zum Vorwand. Auch jetzt spricht der Pädagog wieder an Stelle der Kinder, sie sind wieder stumm. Als er das zu Meldende gesagt hat, entläßt ihn die Mutter. In der folgenden Szene zwischen Mutter und Kindern stört seine Gegenwart, die Kinder brauchen den Führer nicht mehr, sie selbst hat sie ja an der Hand, mit ihr gehen sie dann auch ab. In der leidenschaftlichen Szene, in der sie den entsetzlichen Entschluß des Kindermordes mit sich hin- und herwälzt in Sehmerz und Zorneswut, wagt der Dichter die Kinder auf die Szene zu stellen, aber er wagt nicht sie auch nur ein Wort selbst sprechen zu lassen auf all die herzzerreißenden Schreie der gequälten Brust der Mutter. Und gerade dadurch erreicht er sein Ziel. In die Worte der Mutter kann er all die Innigkeit, das Zarte des Kindes hineinlegen, ein Kind selbst könnte das nicht ausdrücken. „Noch einen Gruß den Söhnen“, setzt sie sich zur Ruhe und Kälte zwingend ein; von Wort zu Wort aber, das sie zu den Kleinen spricht, wird sie wärmer, inniger, rührender. Wir glauben die heißen Umarmungen in den Worten vor uns zu sehen:

\section{Reieht, o Kinder, reicht}

Der Mutter eure Rechte, sie zu küssen, dar.

O liebe Hände, lieber Mund, liebreizende

Gestalt, o meiner Kinder edles Angesicht!

Ja werdet glücklich, aber dort! Der Erde Glück

Nahm euch der Vater. Lieblich hold Umfangen, ach,

Du süfer Hauch des Atems, weicher Wange Rot!

Geht, geht, o Kinder: ich vermag nicht länger mehr

Euch anzublicken, ich erliege meinem Leid. $\left.{ }^{2}\right)$

Die grause Tat selbst entrieht der Dichter schonend unsern Augen. Doch von innen dringen die Jammerrufe der Kinder:

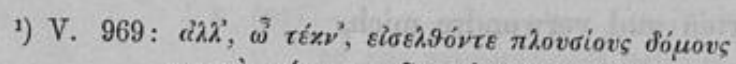

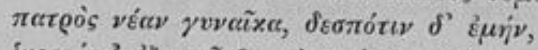

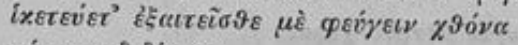

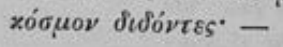

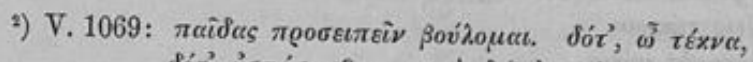

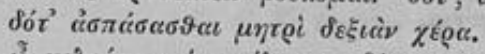

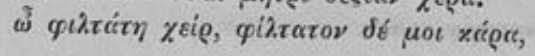

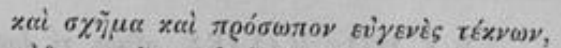

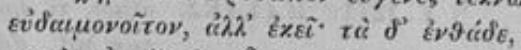

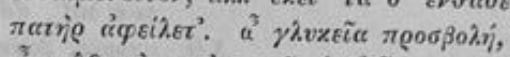

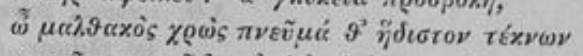

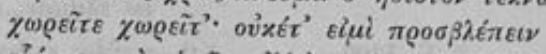

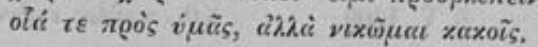


Weh, was beginn' ich? Wie entfliehn der Mutter Hand?

und: Ich weiß es nicht, mein Bruder, sterben müssen wir.

Der Chor gibt die Erklärung:

Hörst Du der Kinder Wehruf, hörst Du ihn?

O unholde Mutter, unselig Weib! $\left.{ }^{1}\right)$

Die Stimmen der beiden Söhne rufen nochmals vereint um Hilfe. Die entsetzten Worte des Chores bestätigen uns, daß die Tat geschehen ist. Wie Iason herbeieilt, erfährt er:

Tot sind die Söhne, durch der Mutter Hand entseelt. ${ }^{2}$ )

Gleich darauf erscheint Medea mit den Leichen auf einem Drachenwagen in der Luft. Die Rufe hinter der Szene konnten Erwachsene mit verstellten Stimmen für die Kinder erschallen lassen. Und so wird es auch gewesen sein, Kinderstimmen von hinter der Szene her hätte man kaum im ganzen Theater verstanden (vgl. dazu auch Haym a. a. O. S. 6).

Nicht ganz so einfach liegt die Frage in der Andromache. Wir finden da den Knaben Andromaches, Molottos, der lebhaft auf der Szene spricht (V. 490-513), in Wechselrede mit der Mutter jammernd um den ihnen gemeinsam drohenden Tod. Das Leichteste wäre, ihn von dem Tritagonisten spielen und sprechen zu lassen; aber Molottos ist noch ein Kind, kein Jüngling (vgl. V. 548 und bes. 732), und er kommt in der nächsten Szene selbviert, neben Peleus, Menelaos und Andromache, vor, könnte also nicht von einem der drei Agonisten gegeben werden. Aber auch hier gibt genauere Beobachtung den Aufschluß: In dieser letzteren Szene, da Peleus den Leidenden zu Hilfe kommt und mit dem Knaben zusammen Andromaches Fesseln löst, spricht der Knabe kein Wort, und seine Handlung wird durch die Worte des Ahnherrn kommentiert (vgl. V. 514, 699 f., 724). Sollte das nicht ein Fingerzeig dafür sein, daß in der vorigen Szene der Tritagonist, der erst nachher als Peleus auftritt, hinter der Szene die Worte des Knaben gerufen habe, während vorn auf der Bühne ein Knabe als Molottos figurierte? Sowie Peleus erscheint, kann Molottos nicht mehr sprechen, und es wäre doch recht wahrscheinlich, wenn er zum rettenden Ahn oder zur befreiten Mutter ein Wort über die Erlösung spräche. Der Dramaturg Euripides verbot es dem Dramatiker.

In den Herakliden sind die Kinder des Herakles durch Knaben leicht darstellbar. Sie sind stumm, und selbst wo sie direkt angeredet werden, ergreift Jolaos für sie das Wort.

Noch deutlicher tritt dieses für die Kinder Reden der Erwachsenen und ihr Beschreiben der Kinderhandlungen im rasenden Herakles hervor, wo (V. 73 ff.) die Mutter wörtlich für sie spricht, erzählend:

Sie kommen forschend, eines hier, das andre dort,

Und sprechen: „Wo denn, Mutter, ist der Vater hin?

Was tut er denn? Wann kommt er?" So in Kindeswahn

Verlangen sie den Vater: ich zerstreue sie,

Ich tröste sie mit Worten und verwundre mich,

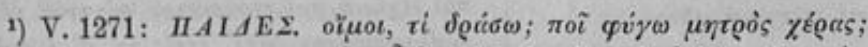

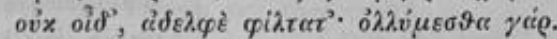

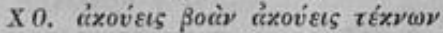

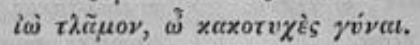

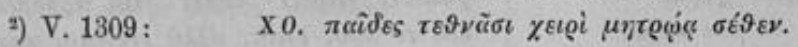


Wie jedes hebt die Füße, wann die Pforte knarrt,

Sich hinzuwerfen an des Vaters teures Knie. ${ }^{1}$ )

Die korrespondierende Stelle ist dann die wirkliche Begrüßung des Vaters, wie der Ersehnte überraschend heimkehrt. Die Kinder hängen sich an den Vater Herakles, er kann sich ihrer kaum erwehren:

Lasset ab von meinem Kleid:

Denn Flügel hab' ich keine, will euch nicht entflieh'n!

$\mathrm{Ha}$ !

Sie weichen nicht, nein, klammern um so fester sich

An mein Gewand.

Ich will sie führen, will sie mir, gleich wie das Schiff

Die Boote, nachziehn; denn um meine Kinder mag

Ich gern mich müh'n! $\left.{ }^{2}\right)$

Das können Knaben darstellen, und die Worte des Vaters und das tolle Treiben der Kinder ergänzen sich zu charakteristischer, weil hier beabsichtigt halb komischer Wirkung der Familienszene, einen um so ergreifenderen Gegensatz bildend zu dem Verderben, das der Wahnsinn des Vaters bald darauf den Kleinen bringt. Feinfühlig verschont uns der Dichter mit dem Anblick der Ermordung. Der Botenbericht bringt die Schilderung der gräßlichen Szene, den Wortlaut der Klagen der Kinder erschütternder, als es durch Kinder auf der Bühne dargestellt und gesprochen werden könnte (V. $922-1015)$. Wie sie zu stummen Leichen geworden sind, öffnet sich hinten die Tür, und man sieht sie blutig um den Vater liegen.

Dieselbe Technik wird in der Hekabe angewandt. Polymestor, Hekabes Todfeind, tritt mit seinen beiden Söhnen auf. Stumm wohnen sie dem Auftritt bei, in dem, wie die Zuschauer ahnen, der furchtbare Racheakt an Vater und Söhnen schon eingeleitet wird. Ahnungslos, erschütternd in ihrer Unschuld, gehen die Knaben mit dem Vater ab - in Hekabes tötliche Netze. Die Tat geschieht hinter der Szene. Die Weherufe des Vaters für sich und die Kinder ertönen aus dem Zelt. Polymestor erzählt hervorstürzend den gräßlichen Mord. Die Notwendigkeit, die Kinder reden zu lassen, hat Euripides umgangen, sie können von Knaben figuriert werden.

Ebenfalls durch einen Knaben zu geben ist der kleine Astyanax in den Troerinnen. Die gleichen Mittel der Begleitworte zu den Handlungen des Kindes finden wir wieder:

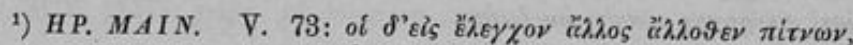

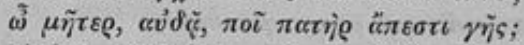

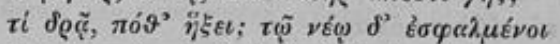

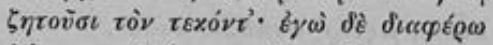

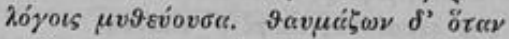

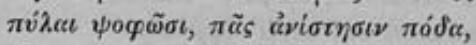

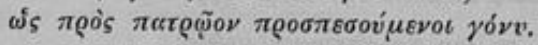

${ }^{2)}$

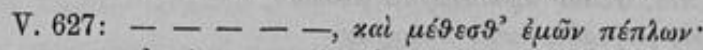

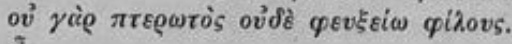

a,

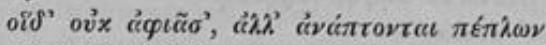

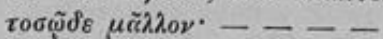

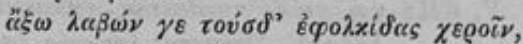

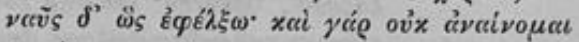

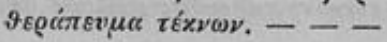


Andromache (beim Abschied, ehe sie gefangen fortgeführt, das Kind vom Turm gestürzt wird):

Du weinst, o Söhnchen? Ahnest du dein Mifgeschick?

Was hältst du, Kind, mich, hängst dich fest an mein Gewand,

Und schmiegst in meine Flügel dich, dem Hühnchen gleich?

O du, des Mutterarmes zarte, liebe Last!

O süßer Hauch der Lippen! - - -

Zum letzten Male wirf ans Herz der Mutter dich,

Umfange, die dich geboren! Schlinge deinen Arm

Um meinen Nacken, füge Mund an Mund, o Kind! $\left.{ }^{1}\right)$

Taltybios reißt ihn aus der Umarmung der Mutter:

Auf, Sohn, laß ab von dem holden Gespräch

Mit der trauernden Mutter, und steige mit uns

$\mathrm{Zu}$ der heimischen Burg Turmzinnen empor,

Wo der Danaer Schluß dir zu sterben verhängt!

(zu den Dienern) Da nehmt ihn! $!^{2}$ )

Und wie die kleine Leiche dann hervorgebracht wird, wie greifen uns da die Worte der Großmutter Hekabe ans Herz, die noch einmal das Bild des holden, lebensfrohen Knaben plastisch vor uns aufleben lassen. So spielt auch dieses Kind seine passive Rolle wirkungsvoll zu Ende.

Kein Knabe, kein Kind braucht der Darsteller des kleinen Orest in der Iphigenia in A ulis zu sein. Es war wohl, wie der Orest im Äschyleischen Telephos, eine Puppe, die man vom Wagen hob. Sie gewinnt Leben, sowie Klytämnestra sie mütterlich anspricht:

Und hier den Knaben, Agamemnons kleinen Sohn,

Nehmt auf, Orestes; denn ein Säugling ist er noch.

Mein Söhnchen, schläfst du? Hat die Fahrt dich eingewiegt? ${ }^{3}$ )

Noch einmal, in der zweiten Hälfte des Dramas wird das Kindchen Orest auf die Bühne gebracht. Wir sehen, durch die Worte der Mutter aufmerksam gemacht, die Puppe für den Säugling an:

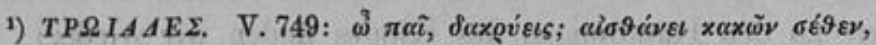

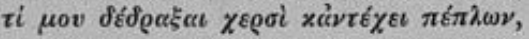

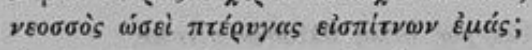

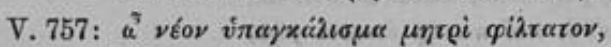

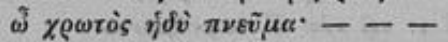

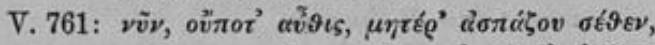

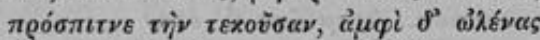

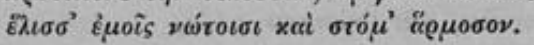

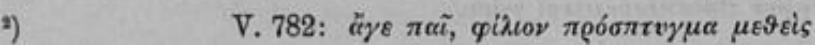

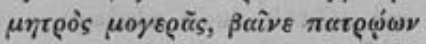

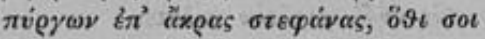

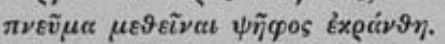
$\lambda \alpha \mu \beta \dot{\alpha} \nu \varepsilon t^{\prime}$ aviróv. - -

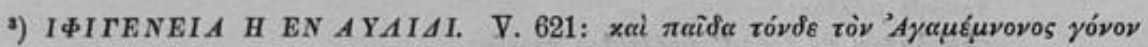

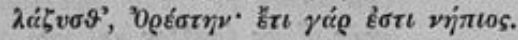

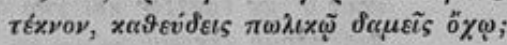


Klytämnestra (nach Iphigenia ins Zelt rufend): Tritt nun heraus, o Tochter,

- - - Und gehüllt in dein Gewand,

Bring auch Orestes, deinen Bruder, mit heraus. $\left.{ }^{1}\right)$

Wie Iphigenia dann den Vater um ihr Leben anfleht, spricht sie zugleich für das unmündige Brüderchen:

Mein Bruder, zwar ein schwacher Helfer bist Du nur

Den Deinen, dennoch weine mit und fleh' ihn an,

Den Vater, deine Schwester nicht zu töten. Traun,

Ein Mitgefühl der Leiden spricht aus Kindern auch.

O siehe! Schweigend, Vater, fleht dein Sohn zu dir; _ - -

Zwei deiner Lieben flehn dich an bei deinem Kinn,

Unmündig noch ist Einer; ich herangereift,

Gedrängt in Ein Wort fass' ich aller Gründe Kraft:

Dies Licht der Sonne schauen ist das Süßeste,

Der Tod so grau'nvoll. Rasend, wer zu sterben wünscht! ${ }^{2}$ )

Wie deutlich weist der Dichter hier selbst auch dem unmündigen Kinde die Rolle an, die es auf der tragischen Bühne wie im Leben spielen kann: „Ein Mitgefühl der Leiden spricht aus Kindern auch," und "Schweigend fleht dein Sohn zu dir."

In den Schutzflehenden treten die Söhne der vor Theben gefallenen Helden auf. Die Frage der Darstellung ist hier besonders schwierig, sie hängt mit dem noch ungelösten Problem der Darstellung der Chöre der Erwachsenen, der Mütter jener Helden und ihrer Sklavinnen eng zusammen. Zu Anfang erseheint der Knabenchor stumm, Adrast spricht für sie. Und wie sie eine Art Ergänzung jenes Chors der Mütter und Sklavinnen bilden, so antwortet dieser Chor der Erwachsenen zugleich im Namen der Knaben, wo es immer nötig wird. Die Knaben spielen stumm mit. Auch im weiteren Verlauf des Dramas sind es nur die Mütter, die als Chor die Handlung begleiten (z. B. beim Heranbringen der Sohnesleichen) oder auch in die Handlung selbst mit eintreten. Dah die Knaben da immer teilnahmlos, untätig dabeigestanden oder an den Altarstufen gelegen hätten, ist unwahrscheinlich, aber der Dichter gibt keinen Anhalt für irgendwelche Handlung derselben. Gegen das Ende jedoch bringen sie die Asche ihrer Väter getragen. Jetzt lösen sich - so scheint es - dabei auch einzelne Stimmen

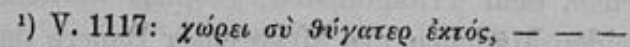

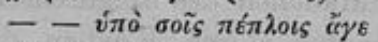

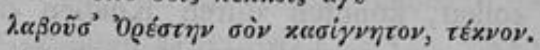

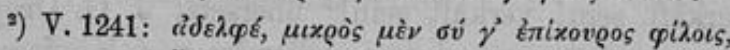

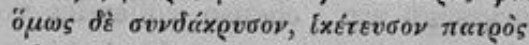

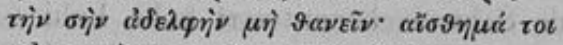

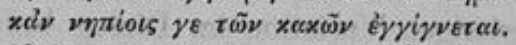

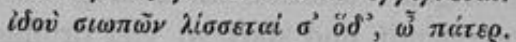

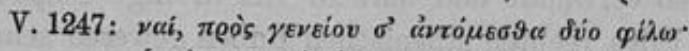

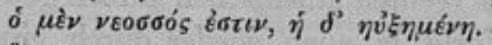
हั

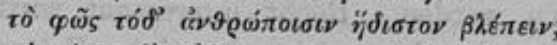

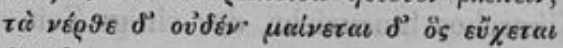
$\vartheta \propto \nu \varepsilon \tilde{\nu}$.

Zum Alter des Orest und der Darstellungsart vgl. Haym a. a. O. S. $17 \mathrm{f}$. 
aus ihrem Chore los, und sie tragen im Wechselsang mit dem Mütterchor das Totenlied, den Threnos, vor. Über einen solchen Nebenchor wie über alle jene Parachoregemata sind wir noch so wenig unterrichtet, daß sich für unsere Stelle nicht entscheiden läßt, ob hier 4 (oder auch 5) Knaben je einzeln gesungen haben (vgl. Alb. Müller S. 220 Anm. 3, Geroldt, Eur. p. 72-78), oder ob es als Chorlied aufgeführt wurde, oder ob es Knaben überhaupt nicht gesungen, sondern nur dargestellt haben (wie oben), während Choreuten für sie sangen, oder ob schlieflich nur ein Teil dieser Stellen hier gesungen, die übrigen gesprochen worden seien. Die Schwierigkeiten der Rekonstruktion der Aufführung der Schutzflehenden sind groß, aber nicht derart, daß sie uns zu der Annahme von Kindesspielern in der griechischen Tragödie zwängen, die wir sonst immer abgelehnt haben. Denn der Umstand ist auch besonders zu beachten, daß Euripides in diesen Knaben nicht Individuen, einzelne Kindercharaktere gezeichnet, sondern sie nur als Teile, als Vertreter des Chores, also als Typen hingestellt hat.

Müssen wir so für die tragische Bühne der Griechen von wirklichen Kinderrollen, durch Knaben dargestellt und gesprochen, absehen, so sollten wir doch denken, daß die ko mische Bühne, daß Aristophanes gern sich des Kindes bedient habe zu seinen heiteren Zweeken. Sahen wir doch schon in der Tragödie die Tatsache, dort eine Gefahr, hier ein Vorzug, daß die Erscheinung, Sprache und Bewegung des Kindes nur zu leicht die Heiterkeit der Zuschauer erregt. Ist doch der Humor die sicherste Brücke, die wir zur Eroberung der Welt des Kindes schlagen können, und spielt das Kind selbst doch nur zu gern Komödie, verkleidet sich und ahmt Erwachsenen mit drolliger Ernsthaftigkeit eifrig nach. Ja ist doch auch dem Kind noch viel unmittelbarer als dem Erwachsenen und noch nicht durch den Zwang der Sitte gestört, der natürliche Trieb der Nachahmung mit einem lustigen Zug zur Satire und Karikatur eingeboren. Sollte sich alles dessen der Komödiendichter nicht bedienen?

Ein Überblick über die Dramen des Aristophanes lehrt zunächst, daß im Lustspiel durchaus nicht mehr Kinder vorkommen als im Trauerspiel. Und wenn wir nun wirklich tragische, erschütternde Kinderszenen bei den drei Tragikern gegen wirklich auf das Kind gestellte komische Szenen bei Aristophanes abwägen, so fällt die Entscheidung noch mehr zu Gunsten der ersteren. Lassen wir die Stücke wieder unter dem gleichen Gesichtspunkt an uns vorüberziehen:

Die Tochter des attischen Landmannes Dikaiopolis in den Acharnern (V. $237 \mathrm{ff}$.) ist kein Kind mehr, sie konnte von einem Erwachsenen, dem Tritagonisten, gespielt werden. Die Anzüglichkeiten haben sonst keinen Sinn. Die beiden Mädchen des Megarenser Bauern dagegen, die als Ferkel verkleidet verkauft werden sollen, konnten durch Knaben dargestellt werden. Ihre einzige kurze Rede im Dialekt (,verkáft sein! verkáft sein!"“ übersetzt J. G. Droysen ${ }^{1}$ )) konnte, zumal das Wort ihnen vom Vater vorgesagt war, ebenso vollendet von Kindern nach-

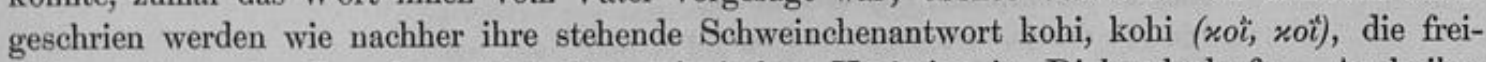
lich mancher reizenden aber nicht allzu schwierigen Variation im Dialog bedurfte. Auch ihre Aktion ist dem kindlichen Tiernachahmen so verwandt und darf so viel drollige Ungeschicklichkeit verraten, daß es wahre Bravourrollen jedes rechten athenischen Buben gewesen sein müßten. An sich, der Rollenzahl nach, konnten die Worte ja auch wieder durch einen der nicht beschäftigten Schauspieler cachiert gesprochen werden. Recht interessant wird die Frage nun, wenn man eine Bemerkung V. 909 über Nikarchos hinzuzieht, der einige Zeit nach jener Ferkel-

1) Des Aristophanes Werke. Ubers, von Joh. Gust. Droysen. 3 Teile. Berlin 1835, 1837, 1838. 


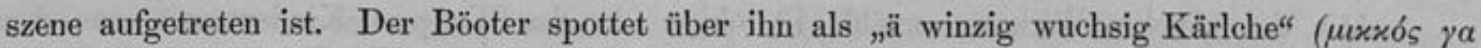
$\mu \tilde{a} x o s$ oṽ $\left.{ }^{2}\right)$. C. Beer ${ }^{1}$ ) folgert aus der Tatsache, daß in den Wespen die lichtertragenden Knaben später wahrscheinlich die kleinen Karkiniten dargestellt hätten (ich komme unten darauf zurück), als nicht minder wahrscheinlich, daß der Dichter auch hier zur Erzielung komischer Wirkung den kleinen Nikarch durch ein Kind habe darstellen lassen, das als Töchterchen des Megarers bereits auf der Bühne gewesen sei. Ich möchte umgekehrt folgern, daß, wie jene Karkiniten auf zwerghafte Choreuten hinweisen, auch an unsrer Stelle ein solcher kleiner Choreut den Nikarch, der ja von Beer S. 57 als überzählig nachgewiesen wird, gegeben habe, vielleicht auch schon vorher das eine redende quiekende Töchterchen. Auch mir scheint dagegen wie Beer die Ansicht Otfr. Müllers (Gesch. d. Griech. Lit. II S. 205) unhaltbar zu sein, daß jene Ferkelchen-Mädchen Puppen gewesen sein sollten. Die verfänglichen Witze wären da ganz verloren gegangen.

Der Knabe, der in den Rittern (V. 1384 f.) dem Mann aus dem Volke den Klappstuhl nachtragen soll, ist nur Statistenkind, kein Darsteller. Dagegen erzählt vorher ( $V .417 \mathrm{ff}$.) derselbe Wursthändler einen drolligen Bubenstreich aus seiner eignen Jugend mit aller Anschaulichkeit:

Ich kann mit manchem Schabernack aus meiner Kindheit dienen;

So führt' ich einst die Köche an, indem ich sprach zu ihnen:

„Da seht doch, Bursche! seht ihr nicht? der Frühling kommt, die Schwalbe!“

Da sah'n sie hin, ich stahl indes ein Nierenstück vom Kalbe.

Chor: Du allerliebstes Nierenstück, das heiß ich doch gewitzet:

Wie „Letsche, bevor die Schwalbe kommt", ein Stückehen Fleisch stibitzet!

Wursth.: Und tat ich das, so blieb's geheim; sah's einer gar von den Lümmeln,

Flugs nahm ich's zwischen die Beine da, schwur's ab bei allen Himmeln.

Drum sprach ein Staatsmann einst zu mir, der's sah, ein großer Denker:

„Nicht fehlen kann's, der Junge wird noch einst des Volkes Lenker!“2)

Der Erzähler erzielte größere Bühnenwirkung damit, als wenn ein Kind solche Szenen selbst hätte aufführen sollen.

Wir sehen, wie klar auch Aristophanes sich der Grenzen einer Schauspielkunst an Kindern bewußt ist, wie er durchaus die Komik von Kinderszenen zu schätzen weiß, wie er sie aber nicht der eigenen Darstellung durch Kinder anvertrauen mag. Das Kind auf der Bühne wirkt nur unfreiwillig komisch, wie wir sahen, daß es nicht beabsichtigt tragisch wirken kann. Soll eine bewußte Wirkung erzielt werden, so muß ein Erwachsener mit wirklicher mimischen Kunst die Führung der Szene in die Hand nehmen, oder der dramatische Auftritt muß in einen epischen Bericht umgesetzt werden.

2) Über die Zahl der Schauspieler bei Aristophanes. Leipzig 1844. S. 58.

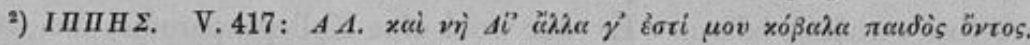

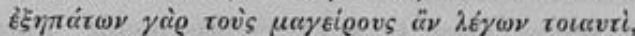

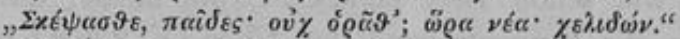

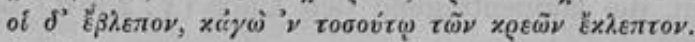

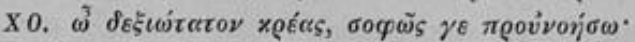

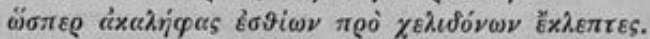

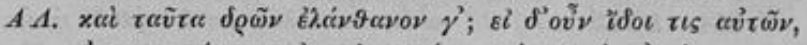

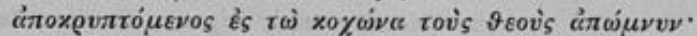

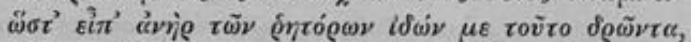

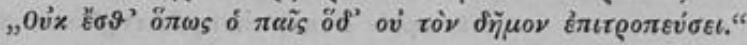


Mit der gleichen Wirkung erzählt Philokleon in den Wespen Kinderszenen aus dem eigenen Richter- und Privatleben voll dramatischer Lebendigkeit. Die Knaben aber, die im selben Lustspiel auftreten, haben keine eigene dramatische Leistung zu vollbringen. Eine Gruppe von lampentragenden Knaben begleitet in der Nachtszene (V.230f.) als eine Art Kinderehor den Chor der Greise. Launig genug klingen die Worte des einzeln sprechenden oder singenden Knaben, wenn er lustig den Alten, den Chorführer, vor dem Kot des Hofes warnt:

Der Kot da! he Papa! Papa! mußt da nebenher gehn!1)

Schauspielerische Anforderungen erhob die Stelle nicht. Auch die Aktion des Lichtschneuzens wird dem Jungen keine zu große Schwierigkeit geboten haben. Wie er's aber ungeschickt, statt mit einem Strohhalm, mit den Nägeln macht, erzielt er zum Lohne erst seine eigentliche dramatische Leistung: er wird durchgeprügelt. Da setzt der freche Kerl mit den komisch fluchenden Strophen zur Drohung ein:

Setzt ihr noch einmal uns zurecht, Wetter! mit euren Schmissen,

So heißt's, ihr Jungen, Lampen aus! hurtig ausgerissen!

Dann, Alter, hier im Dunkeln du, ohne Licht und Leiter,

Trotz einem Rohrspatz plansche dann durch den Dreck dich weiter! ${ }^{2}$ )

Die Worte des einzeln Sprechenden könnten wohl, wenn die Knabendarstellung trotz aller Einfachheit Schwierigkeiten machen sollte, durch einen Agonisten gegeben worden sein. Dasselbe gilt auch von der Fortsetzung des Dialogs des Alten mit dem Knaben, des Choregen mit einem Choreuten (V. 290-316), ich kann mich nicht Hayms Ansicht (a. a. O. S. 20) anschließen, $\mathrm{da} B$ diese Partie, die freilieh im gleichen Versmaß wie der vorhergehende Chorgesang gehalten ist, auch vom ganzen Chor der Alten und dann einem Chor der Knaben gesungen worden sein soll. Es ist zu sehr persönlicher Dialog und Aktion des Alten mit dem einzelnen Jungen, die ja sehr wohl als zwei Einzeltypen aller Alten und aller Jungen gelten können. Das Versmaß kann eine Travestie der Chorstrophe sein. Philokleon nimmt es ja (V. $317 \mathrm{ff}$.) ebenso auf und setzt es fort.

Die von mir schon oben (S. 13) herangezogene Stelle gegen Ende der Wespen (V. $1501 \mathrm{ff}$.) dürfte vielleicht auf solche Knabendarstellungen von geringerer Bedeutung ein Licht werfen: Ein Ballet der Karkiniten, zwergartiger Kerle, macht den satirischen Schluß. Es wird überliefert, daß es zur Zeit des Thespis und Phrynichos einen Tragöden Karkinos gegeben habe. Sein Enkel, wieder Karkinos genannt, hatte 4 (nach andern 3) Söhne. Der eine war der Tragödiendichter Xenokles, die andern waren Choreuten und wegen ihrer Kleinheit und Beweglichkeit bekannt. Sie werden hier von Aristophanes verhöhnt. Sollte das nicht darauf hinweisen können, daß durch solche auffallend kleine und bewegliche Choreuten, wie die Karkiniten, gelegentlich auch die Kinderrollen dargestellt worden sind? Doch ist deshalb nicht daran zu denken, daß die Karkiniten sich hier bei der Aufführung an den Lenäen 422 etwa selbst dargestellt und somit sich selbst verhölnnt hätten. Es war wohl eine Kollegenparodie, die da geübt wurde. Es mögen, wie schon Beer (a. a. O. S. 50) meint, dieselben darstellenden, tanzenden Knaben gewesen sein, die lampentragend den Chor (V. $230 \mathrm{ff}$.) begleiteten. Ob dieses Knaben-

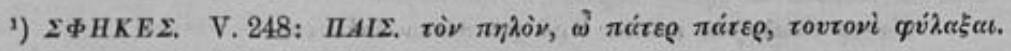

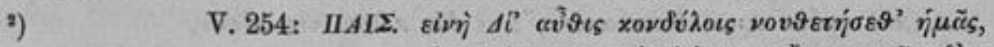

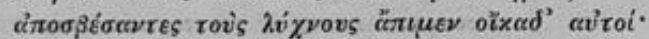

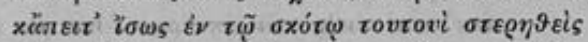

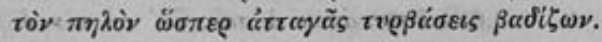


ballet nun aus 3, 4 oder mehr kleinen Statisten bestanden hat, ist für unsere Frage von untergeordneter Bedeutung (vgl. aber Haym a. a. O. S. 19-21).

Eine besondere Stellung zu unserer Frage nehmen die beiden Paare von Kindern im Frieden ein. Das ganze Stück ist so sehr politische und literarische Satire, daß die Personen darin uns fast alle mehr symbolische Gestalten als wirklich individuelle Charaktere zu sein scheinen. Auch die Kinder. Die Töchterchen des Mistkäferreiters Trygaios (V. 114-148) sind nicht nur unkindliche, etwa altkluge Kinder; das sind überhaupt keine Kinder, die den Euripides so beständig und so komisch im Munde führen, die auf die väterlichen Wortspiele mit topographischen Namen so beschlagen eingehen und so karikiert schwülstig nach Tragikerart sprechen. Wenn manche Gelehrte meinten (vgl. Beer S. 15), alle Kinderrollen seien im Athenischen Theater Erwachsenen zuerteilt worden, deren Kleidung symbolisch das Kindesalter angedeutet habe, so scheint diese uns sonst nicht zusagende Ansicht hier am ehesten am Platze zu sein. Auch die Rollenverteilung macht keine Schwierigkeiten. Der Knecht (oixźt $\eta \varsigma$ A.), der vorher noeh mit Trygaios sprach, ist abgegangen, unter dem Vorwand, die Kinder zu rufen. In dieser Kinderszene sind nur drei Personen auf der Bühne, der Protagonist als Trygaios, der Tritagonist, der vorher den zweiten Knecht gegeben hat, nachher als Polemos, dann als Hierokles, als Sichelschmied und als Helmschmied mit rasch gewechselter Maske wieder erscheinen wird, und ein statistierender Choreut als stumme zweite Tochter. Der Deuteragonist ist nicht auf der Szene, er zieht sich um vom ersten Knecht zum Hermes, dann Kydoimos und Waffenkrämer (vgl. Beer a. a. O. S. 45). So wäre alles in schönster Ordnung, wenn nicht ein Skolion zu dieser Stelle (zu V. 114 ff.) gerade die viel besprochene, umstrittene und, wie wir eingestehen müssen,

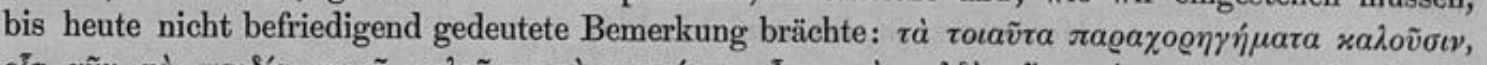

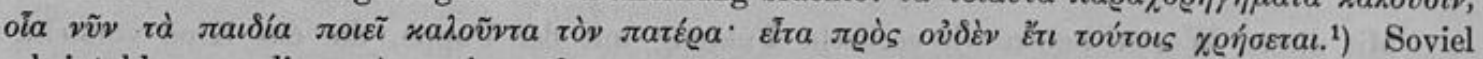
scheint klar aus dieser Anmerkung hervorzugehen, daß der Choreg etwas mit der Darstellung dieser Kinder zu tun hatte, und daß diese Leistung über seine gewöhnliche Verpflichtung, den Chor zu stellen, hinausgriff. Ob es nun aber heißen soll, daß der Choreg nwei Knaben hierfür herbeizubringen und einzustudieren hatte, oder ob zwei Knaben vorn statistierten, während hinten ein Choreut für sie spräche, oder ob zwei Choreuten die beiden Töchter darstellten und sprachen, wissen wir nicht. Wenn wirklich hier unter Parachoregema verstanden werden sollte, daß der Choreg Knaben als eigentliche Kinderspieler auszubilden hatte, so wäre das Beispiel dieses unkindlichen Kindes sehr ungeschickt gewählt gewesen, und ich möchte aus diesem als dem einzigen Beispiel bei Aristophanes nicht auf eine eingeführte Institution von Kinderspielern schließen oder darauf, daß der griechische Dichter an eigentliche Knabenrollen gedacht hätte. Auch dürfen wir uns, wie E. Bethe, a. a. O. S. 6, betont, durch die späteren Angaben der Scholiasten und des Pollux keineswegs unsere Auffassung von der Aufführungsart der Dramen der klassischen Zeit unbedingt bestimmen lassen. Vielleicht erhalten wir noch einmal über die

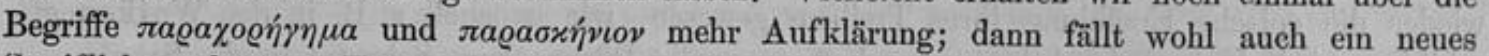
Streiflicht auf unsere Frage.

Die beiden Knaben, die gegen Ende des Stückes nacheinander von Trygaios auf die Bühne gerufen werden, sind Sänger eines Knabenchors, wie er bei Festgelagen gebräuchlich war. Beide Rollen waren von Knaben leicht darstellbar, da sie nur wie zur Probe aufzusagen hatten, was der Knabenchor singen sollte. Schauspielerische Aufgaben sind nicht damit ver-

1) Schol. graec. cod. Venet. bibl. Marc. 474. Vgl. Fr. H. M. Blaydes, Aristoph. com. V. p. 141. - Vgl. auch Alb. Müller a. a. O. S. 177. 
bunden, auch sie verlangen keine kunstmäBig ausgebildeten Kinderspieler. Es liegt nahe, anzunehmen (so bei Beer S. 45), daß die gleichen Darsteller für beide Kinderpaare des einen

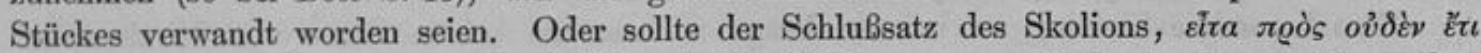

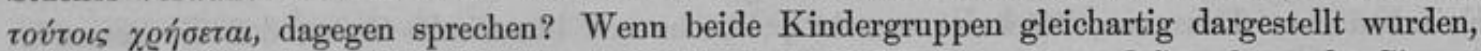
so könnte man auch wieder an stummes Agieren durch Kinder vorn und Sprechen oder Singen durch Choreuten hinter der Szene denken. Bestimmtes läßt sich hier weniger als sonstwo sagen, die auseinanderlaufenden Ansichten der Forscher über diese Frage ${ }^{1}$ ) zeigen die Unklarheiten und Widersprüche der Skolionworte.

Die Technik des Sprechens eines der Schauspieler auf der Szene für ein Kind neben ihm wurde wohl in der Lysistrate angewandt. Kinesias bringt hier sein kleines Kind, um die Mutter zu sich zurückzugewinnen, an deren Brust das Kleine noch gelegen hat. Er läßt das

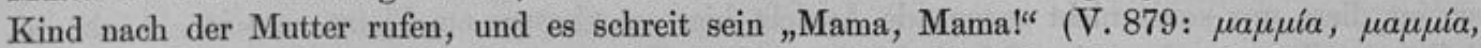
$\mu \alpha \mu \mu^{\prime}(\alpha$.$) Ein so kleines Kind kann sich natürlich nicht selbst darstellen, und die bekannten$ ersten Babyworte werden keinesfalls von einem so jugendlichen Schauspieler aufs Stichwort gebracht worden sein. Kinesias selbst konnte das "Mama" des durstigen Sprößlings nachahmen (vgl. Beer S. 96), und dieses Auftreten des Kleinen, der wieder wie der kleine Orest (s. o. S. 2 und 10) eine Puppe sein konnte, wird einen guten Lacherfolg gehabt haben. Das genügt aber dem Dichter nicht, er will rühren, das Herz der Mutter und das Publikum. Und er tut es. Ein paar Worte der Mutter genügen. Was alle Schmeichelreden des verlassenen Mannes nicht vermocht hatten; das Stimmchen des Kindes hat es erreicht: Sie ruft die einfachen, schönen Worte:

\section{O Mutterherz, ja, ich muß hinab!2)}

Mit diesen Worten haben wir seelische Fühlung mit der Puppe, die das Kind vorstellt, gefunden. Es ist uns zum kleinen Menschen geworden, und wir fühlen ganz mit der Mutter, wenn sie nun mit ihm spricht:

Mein süßer Liebling, o du bösen Vaters Kind,

Komm, laß dich küssen, Muttersöhnchen, du Herzenskind! ${ }^{3}$ )

Sie küßt das Kind und - es ist ja die tolle Komödie - läuft wieder davon.

$\mathrm{Daß}$ solche Darstellung kleiner Kinder durch Puppen auf der Bühne von Athen üblich war, darauf dürfte eine Satire des Aristophanes selbst hindeuten. In den Thesmophoriazusen entführt der freche Mnesilochos einer Frau ihr Kind. Als Geisel will er es töten. Er wickelt es auf und - findet statt des Kindes einen gefüllten Weinschlauch, dessen Inhalt er sich als das Blut des Kindehens in die Gurgel verzapft. Die Enthüllung mag Heiterkeit genug erregt haben.

Die wirkungsvollste Darstellung des Kindes auch auf der Lustspielbühne ist immer wieder die epische Erzählung ihres Treibens gewesen, wie es auch z. B. in den Wolken geschildert wird: Strepsiades bringt seine hoffnungsvolle Pflanze zum Sokrates in die Schule:

1) Vgl. O. Müller, Rhein. Mus. V. 343, C. Fr. Hermann, disputatio de distributione personarum inter histriones in trag. Graec. 39 einerseits; Schneider, Att. Theater S. 138, Lachmann, Jahns Jbb. Jahrg. IX. Bd. 31 , S. 458 , C. Beer a. a. 0. S. 45, andrerseits.

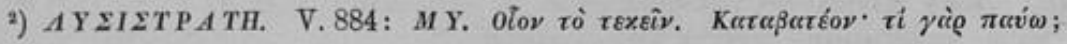

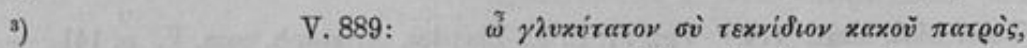

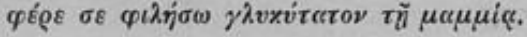


Getrost, versuch's mit dem Lernen nur; er hat Talent,

Er war so ein winzig Bübchen noch, da schnitzt' er schon

Aus Bork' sich Kähnchen, machte von Wachs sich Häuserchen,

Schnitt kleine Hottowagen artig in Leder aus

Und Fröschchen aus 'ner Apfelschale, du glaubst es nicht. ${ }^{1}$ )

Das ist volles Leben des Kindes. Das Beste daran ginge verloren, wenn es sich selbst darstellen müßte, die Naivetät.

Wir kommen nach alledem zu dem Schluß, daß auch Aristophanes auf seiner Komödienbühne sich keines eigentlich dramatisch agierenden Kindes bedient hat. Wo Kinder vorkommen, statistieren sie nur, ihre Leistung ist eine im wesentlichen passive. Die attische Bühne hat also keine Kinderschauspieler, und wir dürfen hierin nicht ohne Staunen die weise Beschränkung der Dichter von Athen aufs neue erkennen. Sie zogen nur das für ihre dichterischen Zwecke heran, dessen Wirkung sie kannten. Sie wußten ganz genau, daß eine beabsichtigte mimische Kunstleistung von einem Kind nicht zu verlangen, ja nicht zu wünschen ist. Nicht, weil sie die Psychologie des Kindlichen noch nicht erfaßt hätten, wie einige (vgl. z. B. Poritzky a. a. O.) meinen, sondern gerade weil sie die Seele des Kindes tief verstanden, wußten sie, daß eine dem Kind angelernte schauspielerische Darstellung nur zufällig gelingen kann, nicht beabsichtigt und nie künstlerisch wahr, und daß solche Abrichtung Gefahr läuft, entweder am unrechten Orte lächerlich oder affektiert zu wirken.

Diese Weisheit hat die ganze Geschichte der Schauspielkunst bestätigt. Sie scheint sehr einfach und selbstverständlich zu sein, und sie hängt mit den tiefsten Problemen der Darstellungskunst zusammen. Wir kennen Wunderkinder in der Musik, die ernsthaft genommen werden müssen, aber wir kennen kein solches Wunderkind der Schauspielkunst. Diese Kunst der Menschendarstellung ist zu eng der Plastik und Malerei einerseits und der Dichtkunst andrerseits verwandt, als daß sie, bei der die Person des schaffenden Künstlers zugleich sein Material ist, ein Kind als Schöpfer und Geschöpf vertrüge. Das Kind aber, dem solches zugemutet würde, ginge zugrunde. Und so mufte wegen dieses einerseits zu wertvollen, andrerseits unbrauchbaren Materials, soweit der Dichter an sein Werkzeug dachte, die Dichtkunst darauf verzichten, diese ganze Seite des menschlichen Lebens lebendig auf die Bretter zu stellen.

Anders könnte es in einer nicht kunstmäßig gebildeten Dramatik der Fall sein. Dem Volksmimen sind seine Mittel gleichgültig. Er macht alles möglich, und er schont niemanden. Und wie die Mimographen Griechenlands ohne Scheu schon die Frauen agierend auf ihre Bühne brachten, so scheinen sie auch Kinder in ihren Truppen, die auf familienhafter Prinzipalschaft beruhten, mit sich geführt zu haben. H. Reich, Der Mimus Bd. I. Berlin 1903, hat uns von diesen Mimen, auch schon der ältesten griechischen Zeit, viel Neues erzählt. Einen klaren Einblick in die Zustände und Erscheinungen vermögen wir trotz aller Rekonstruktionskünste nicht zu gewinnen, da uns die Denkmäler bis auf ein paar kärgliche Reste verJorengegangen sind, und die Überlieferung von ihnen sich fast nur auf dunkle Andeutungen beschränkt. Wir dürfen seit Reichs Buch diese verachtete Nebenseite des griechischen Theaters aber nicht mehr ganz übergehen, und so müssen wir auch in der Frage nach dem Kinder-

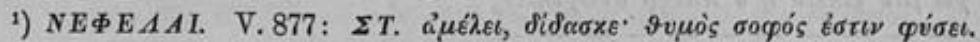

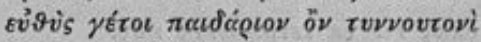

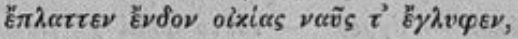

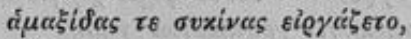

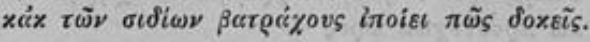


darsteller den Mimus mit heranziehen. Wirklich sind in den wenigen Resten dieser volkstümlichen derben Literatur einige Kinder erhalten. H. Reich weist (S. 602) auf ein Kind bei Sophron hin, indem er sich auf eine Bemerkung des Choricius ${ }^{1}$ ) bezieht. Auch auf ein paar Szenen bei Herondas und bei Theokrit kann er fußen.

Der böse Bube Kottalos im dritten Mimiambus des Herondas, dem „Schulmeister", ist ein Prachtskerl in realistischer Gassenszenerie, und er wird selbst in seiner Sünden Maienblüte auf die Bühne gebracht und wirkte da sicherlich höchst drastisch. Allein: wodurch? Ganz auf dieselbe Weise, mit denselben Mitteln wie seine nicht viel artigeren Kollegen auf der hohen Bühne der klassischen Dramatiker. Dargestellt wird uns nur, wie er von der ob seiner Streiche erbosten Mutter Metrotime zum Lehrer gezerrt und von dem gestrengen Schultyrannen mehr als regelrecht durchgeprügelt wird. Alle seine Schlingeleien, wie er die Schule schwänzt, die Schreibtafel hinter sein Bett wirft, der Mutter aufs Ziegeldach klettert u. a. m. werden uns von der Mutter anschaulich beredt erzählt, wir sehen sie nicht auf der Bühne ausgeführt. Selbst das mangelhafte Lesen und Schreiben des faulen Schulbuben wird uns nicht durch ihn selbst sondern durch den Bericht der Mutter zu Ohren gebracht: „Vorgestern schrieb der Vater das Wort Maron vor: der Wackere hier machte den Maron zu einem Simon! da sagte ich: ich bin eine Törin, daß ich ihn nicht Eselhüten lernen lasse sondern Lesen und Schreiben, in der Meinung, an ihm eine Hülfe einst zu haben in schlechten Zeiten. Wenn wir ihn aber einen Spruch, wie es sich für Knaben schickt, aufsagen lassen, entweder ich oder der Vater, - - da sagt er ihn wie aus engem Loche Wasser tröpfelnd: „A-pol-lon Au-reu“. Das, behaupte ich, wird dir sowohl die Großmutter der Reihe nach aufsagen, und sie kann nicht lesen und schreiben, als auch der erste beste Phryger.“" 2 )

Unwillkürlich, mit sicherem Griff für das darstellbare Komische vermeidet auch der Mimusdichter eine ausgedehntere und eingehendere Aktion und Rede des Kindes. Freilich konnte hierin ja auch die hohe attische Bühne, besonders etwa Aristophanes dem Herondas vorbildlich sein. Ein paar andere Stellen in Fragmenten des Herondas (bei Crusius IX. und ă $\delta \eta \lambda a$ fr. 14) und des Mattius (fr. 3) scheinen, soweit sich aus dem Trümmerfeld der Bruchstücke etwas schließen läßt, auch nur epische Berichte derartiger Max- und Moritzstreiche geboten zu haben.

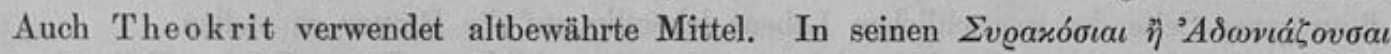
schmäht Praxinoa auf ihren Mann, den „ewigen Quälgeist", in Gegenwart des Söhnchens. Die Freundin warnt sie.

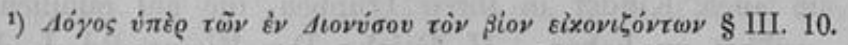

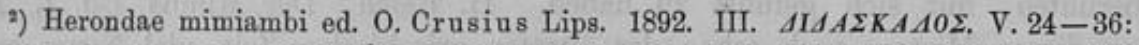

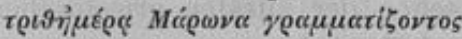

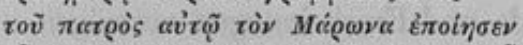

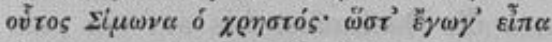

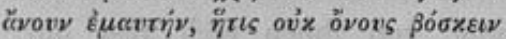

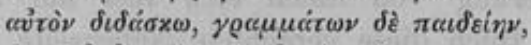

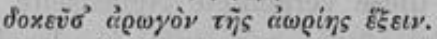

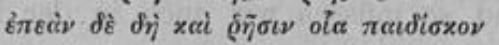

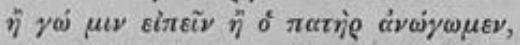

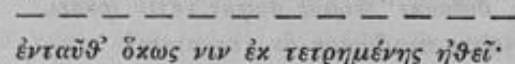

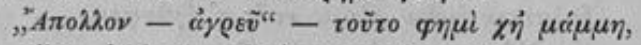

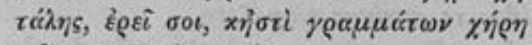

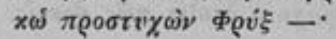


Gorgo: Sprich doch, Beste, nicht so von deinem Dinon; der Kleine

Ist ja dabei. Sieh, Weib, wie der Junge verwundert dich anguckt!

Lustig, Zopyrion, herziges Kind, sie meinet Papa nicht.

Praxinoa: Heilige du! ja, er merkt es, der Bube. - Der liebe Papa, der! ${ }^{1}$ )

Der Junge redet keine Silbe, obwohl sonst dieses Idyll durchaus nicht nur Zwiegespräch enthält. Als die beiden Freundinnen sich dann zum Ausgehen anschicken, scheint sich das Kind an die Mutter zu hängen. Sie übergibt es der Dienerin, und obwohl wir kein Wort, keinen Ausruf des Kleinen hören, empfangen wir ganz den lebendigen Eindruck der Kinderszene aus den Worten der Mutter:

Nicht mitgeh'n, Kind! Bubu da! das Pferd beißt!

Weine, solange du willst; zum Krüppel sollst du nicht werden [in dem Straßengedränge].

Geh'n wir denn. - Phrygia, spiel indeß mit dem Kleinen ein wenig! ${ }^{2}$ )

Über die Aufführungsart dieser ganzen realistisch-dramatischen Gattung wissen wir eigentlich nichts. Soviel steht indessen fest, daß der Mimus nie Anspruch auf kunstmäBige Ausbildung machte; wie sollte er da von Knabendarstellungen mehr verlangen? Einen Keim aber zu reicherer Entwicklung auch des Kindes auf der Bühne barg dieser volkstümliche Zweig des Dramas, das war die weite Mannigfaltigkeit seiner Darstellungsobjekte und Darstellungsarten. Was vom ästhetischen Standpunkt aus eine Schattenseite dieser Gattung ist, sodaß sie in der Literaturgeschichte nie eigentlich hat Bürgerrecht erlangen können, das hat in ihr wie so vielen Objekten der Darstellung auch dem Kinde auf der Bühne erst die eigentliche Existenzmöglichkeit geschaffen: Das ist der Umstand, daß auf der Mimusbühne ohne jede Rücksicht auf künstlerisch schöne Darstellung, ja fast ohne Rücksicht auf eine Darstellungsmöglichkeit überhaupt alles aufgeführt wurde, was irgend im Menschenleben interessant oder amüsant ist. Ein Spiegel des ganzen Lebens wollte diese Bühne sein, sollte da nicht auch mancher Knabenspiegel darunter stecken? Und, insofern diese Mimusliteratur die so oft bestrittenen Überleitungselemente enthält vom antiken zum mittelalterlichen, vom orientalen zum occidentalen Drama (wie Reichs Buch uns jetzt einleuchtend zeigt), insofern bedeutet sie auch für unser Problem einen wichtigen Faktor: Hier liegen die Anfänge des modernen „Kindes auf der Bühne.“

Beide Zweige des antiken Dramas, das höhere und das volkstümliche, sind in späteren Zeiten fortgepflanzt worden. Das hohe Theater von Athen ist durch Renaissance wieder ausgegraben, in andere Literaturen übersetzt und nachgebildet worden, der Mimus hat sich kontinuierlich und organisch fortgesetzt und weitergebildet. Wenn auch die uns erhaltene Mimusliteratur des griechischen $^{3}$ ) Altertums keine bedeutenden Kinderszenen aufzuweisen hat, so genügt das Beispiel,

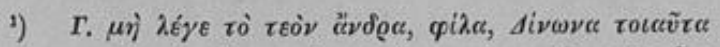

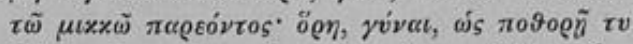

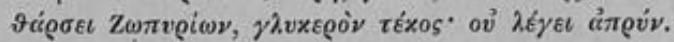

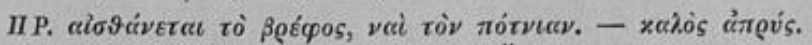

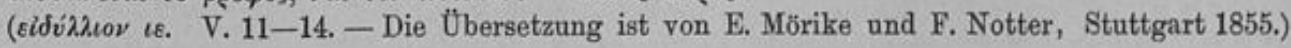

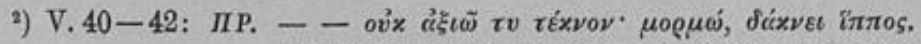

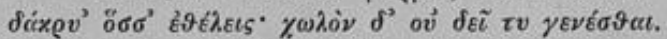

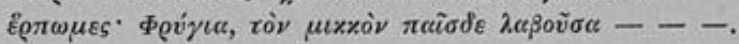

3) Das indische Theater, das auf dem griechischen Mimus fußt, bringt stärkere Erweise der neuen freieren Technik. 
das damit gegeben war: Der Bann war gebrochen, der - wenn auch als Zeichen weiser Mäbigung - doch als ein Hemmnis dem Dichter der klassischen Bühne auf der Seele lag, sowie er an das Erschaffen einer dramatischen Kindergestalt herantrat. Der aus dem Mimus hervorgewachsene Stand des Schauspielers, der sich bemühte, für alle Gebilde der Dichterphantasie adäquate Darsteller heranzubilden, hat auch dem Dichter erst die Möglichkeit gegeben, seiner freischaffenden Lust an den Reizen des ganzen kindlichen Wesens in seiner Komik und in seiner Tragik nachzugehen. Das volkstümliche Drama in seiner Regellosigkeit, wie es durch die hellenistischen Mimen gepflegt und weiterverpflanzt wurde, ist doch die Heimat des Kindes auf der Bühne. Alles andere war nur ein glücklicher Notbehelf in seinem mühsamen Verdecken, Verkleiden und Ersetzen der schauspielerischen Schwäche eines Kindes. $\mathrm{Ob}$ freilich je etwas Gesundes und künstlerisch Schönes zustande gekommen ist durch dieses künstliche Erziehen, beinahe Abrichten von Bühnenkindern zu kleinen Schauspielern, oder ob nicht doch vielleicht die Weisheit der klassischen Zeit des Theaters von Athen in ihrer Mäßigung und ihrem Verzichten recht behalten hat, möge als Problem offen bleiben. Dię Durchführung unsres Themas durch die Theater- und Literaturgeschichte aller Zeiten und Kulturvölker über Seneca und Shakespeare, Lessing, Goethe und Schiller bis zu Ibsen und Gerhard Hauptmann müßte darauf die Antwort geben. 
das damit gegeben war: MäBigung - doch als eir sowie er an das Erschaffer hervorgewachsene Stand d phantasie adäquate Darste gegeben, seiner freischaffe Komik und in seiner Tra wie es durch die hellen Heimat des Kindes auf de mühsamen Verdecken, VeI $\mathrm{Ob}$ freilich je etwas Gesu künstliche Erziehen, beina nicht doch vielleicht die Mäßigung und ihrem Vei Durchführung unsres The Kulturvölker über Seneca Gerhard Hauptmann müßte

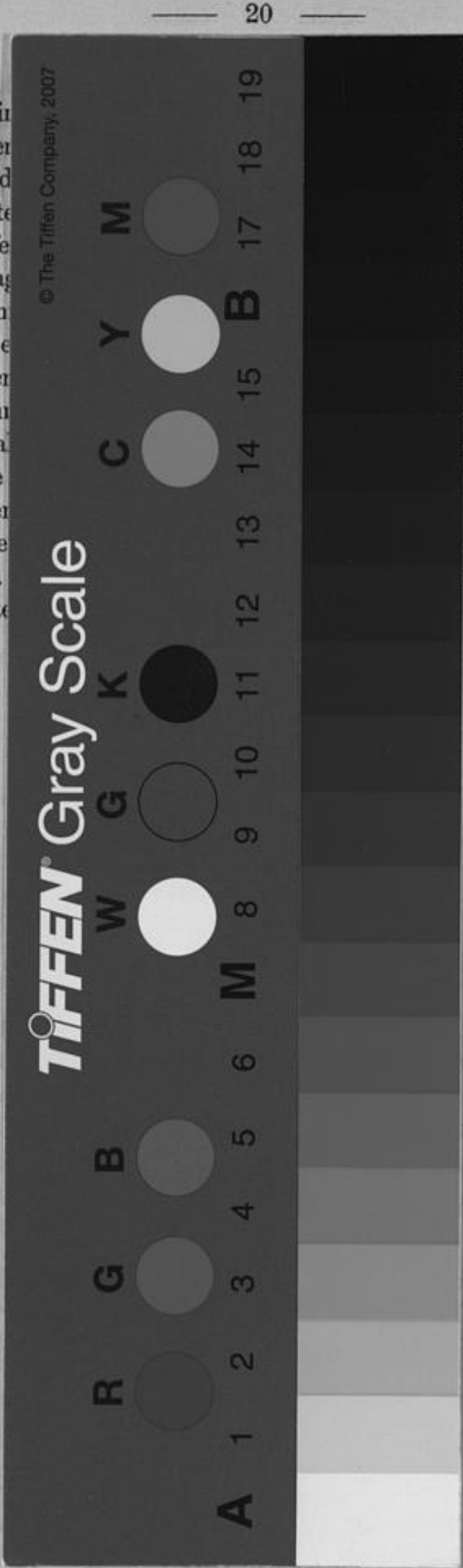

enn auch als Zeichen weiser en Bühne auf der Seele lag, antrat, Der aus dem Mimus für alle Gebilde der Dichterpichter erst die Möglichkeit kindlichen Wesens in seiner rama in seiner Regellosigkeit, rpflanzt wurde, ist doch die ücklicher Notbehelf in seinem schen Schwäche eines Kindes. e gekommen ist durch dieses leinen Schauspielern, oder ob Theaters von Athen in ihrer Problem offen bleiben. Dię urgeschichte aller Zeiten und ad Schiller bis zu Ibsen und 